\title{
Computerized psychiatric interviews: can they help to improve medical care?
}

Department of Preventive Medicine, Faculdade de Medicina da Universidade de São Paulo - São Paulo, Brazil

\begin{abstract}
Studies on psychiatric disorders in Brazil have shown high prevalence rates, both in the community and in primary care centers. However, psychiatric assessments carried out by interviewers have some inherent problems which influence inter-observer reliability. There is great potential for the use of computerized interviews. This article discusses some advantages of this kind of assessment, and indicates a need for investigation into its applicability to Brazilian health care settings.
\end{abstract}

Uniterms: Psychiatric epidemiology. Primary care. Computerized assessments. Case detection.

$\mathrm{E}$ pidemiological studies on the occurrence of psychiatric disorders in Brazil have shown high prevalence rates for these disorders both in the community and among those who are seen in health care services. In a community-based survey carried out in three major urban centers of Brazil ${ }^{1}$ (Brasília, São Paulo and Porto Alegre), the overall prevalence of psychiatric disorders ranged from $30 \%$ to $50 \%$. Anxiety and phobic states were the most common psychiatric disorders, with prevalence rates between $8 \%$ and $18 \%$. The prevalence of major depression among women was twice as high as among men, whereas alcohol addiction was much commoner in men.

About $15 \%$ of the population seek consultations in the primary care sector because of psychiatric problems, but they may not have their problems recognized by their

\section{Address for correspondence:}

Paulo Rossi Menezes

Av. Doutor Arnaldo, $455-2^{\circ}$ andar

São Paulo/SP - Brasil - CEP 01246-903

e-mail: pmenezes@usp.br doctors. Surveys conducted in primary care centers in São Paulo showed that about $50 \%$ of those patients seen by general doctors presented some psychiatric disorder, but their main complaint was related only to physical symptoms. ${ }^{2}$ In one of these surveys, carried out in two primary care centers and one outpatient clinic in a general hospital of São Paulo, rates of detection varied from $10 \%$ to $49 \%$. In another survey, also carried out in the city of São Paulo, with around 1200 patients and 63 randomly selected primary care doctors from 40 primary care units, the mean rate of detection of emotional disorders was $42.3 \%$. In spite of these low rates of detection of psychiatric disorders by primary care doctors, the bulk of all prescriptions of psychotropic drugs is made by general doctors $(46.9 \%)$, followed by cardiologists $(15.3 \%){ }^{3}$

It is possible that these poor detection rates for psychiatric disorders are at least in part explainable by the fact that psychiatric symptoms in such patients appear as a continuously distributed variable. Moreover, psychiatric diagnosis in primary care settings is not reliable due to a lack of standardization in the assessment of such 
symptoms. The development of standardized interview schedules has been shown to be useful in increasing the reliability between different interviewers. However, interviewer-based assessments still have some problems due to differences in: i) the interview techniques used by each professional; ii) perception of patients' speech and behavior by each interviewer; iii) inferences and decisions made by the interviewers on the basis of what they perceived. Such variations are frequent sources of bias, lowering inter-observer reliability.

There is great potential for the development and use of computerized assessments in primary care. ${ }^{4}$ Such assessments may be completed by unsupervised patients, after only brief explanation, and unlike pencil and paper questionnaires, they avoid redundant inquiry, as the presentation of questions depends on previous answers. Thus, this type of questionnaire is an inexpensive selfadministered assessment. Besides this, these assessments are not influenced by the interviewer's knowledge of a patient's characteristics such as sex, race or treatment conditions. There is evidence that answers to socially sensitive questions are more likely to be given in a computerized interview. For example, people admit drinking more alcohol to a computer than to a trained interviewer.

Computerized assessments have an undoubted role in research, as they have better reliability than interviewerbased assessments, and can generate data files ready for analysis, eliminating manual data entry, which is another source of error. Moreover, they may prove to be of clinical value in collecting routine information, and in supporting clinical decisions, because they can supply diagnostic and treatment guidelines, allowing doctors and patients to see the results during consultations.

It is of great interest to know whether such computerized assessments can be used in the medical setting of Brazil, because a considerable proportion of the Brazilian population is illiterate, and such interviews require that the patient reads and answers questions on the computer screen. Furthermore, computers are still something new and threatening to many people in Brazil. Therefore, studies on the applicability of these interviews in public and private medical settings are needed. It is likely that such assessment will prove to be useful in settings where the bulk of those who attend are able to answer a computerized interview. Once it is established where such interviews can be used, clinical trials aimed at examining whether their utilization would improve patients' evolution will become necessary.

\section{REFERENCES}

1. Almeida-Filho N, Mari JJ, Coutinho E, et al. Estudo multicêntrico de morbidade psiquiátrica em áreas urbanas brasileiras (Brasília, São Paulo, Porto Alegre). J ABP-Apal 1992; 14:93-104.

2. Iacoponi E, Laranjeira RR, Mari JJ. Brazil: a giant wakes up to progress and inequality. In: Appleby L, Araya R, editors. Mental health services in the global village. London: Gaskell 1991:131-47.

3. Mari JJ, Almeida-Filho N, Coutinho E, et al. The epidemiology of psychotropic use in the city of São Paulo. Psychol Med 1993;23:467-74.

4. Lewis G, Pelosi AJ, Glover E, et al. The development of a computerized assessment for minor psychiatric disorder. Psychol Med 1988;18:737-45.

\section{ACKNOWLEDGEMENT}

Renata Tirol and Paulo Rossi Menezes have scholarships from CNPq-Brasília, Brazil.

\section{Resumo}

Estudos sobre transtornos psiquiátricos no Brasil têm mostrado altas taxas de prevalência, tanto na comunidade quanto nos centros de atenção primária. Porém, entrevistas psiquiátricas realizadas por entrevistadores apresentam alguns problemas que repercutem na confiabilidade entre diferentes observadores. Há um grande potencial para uso de entrevistas computadorizadas. Este artigo discute algumas vantagens desse tipo de entrevista e aponta para a necessidade de se investigar sua utilização em serviços de saúde brasileiros. 